\title{
Cardiogenic shock without a critically raised left ventricular end diastolic pressure: management and outcome in eighteen patients
}

\author{
DENIS EDWARDS, SEAN WHITTAKER, ALISON PRIOR \\ From Withington Hospital, Manchester
}

\begin{abstract}
SUMMARY Eighteen patients in whom shock developed after acute myocardial infarction are described. There was electrocardiographic evidence of acute inferior infarction in 11, of inferolateral infarction in three, and of anteroseptal infarction in four. In all cases the right atrial pressure was the same as or exceeded the end expiratory pulmonary artery wedge pressure. Plasma volume expansion of $100-2500 \mathrm{ml}$ was needed to produce an optimum pulmonary artery wedge pressure. Eleven patients needed additional inotropic support with dopamine. Despite the absence of a critical increase in pulmonary artery wedge pressure, potential or actual hypoxia was almost always present. Six patients needed endotracheal intubation and mechanical ventilation because they had severe hypoxia that was unresponsive to supplemental inspired oxygen. Life threatening arrhythmias were also common (ventricular fibrillation in seven patients and complete heart block in four). Five patients died. All surviving patients are well and only one requires treatment for heart failure.
\end{abstract}

Shock after acute myocardial infarction is not necessarily associated with a critically high left ventricular end diastolic pressure and in selected patients the cardiac output can be improved and features of hypoperfusion reversed by judicious use of plasma volume expansion. ${ }^{12}$ The introduction of bedside monitoring of pulmonary artery wedge pressure and cardiac output by means of balloon tipped pulmonary artery catheters ${ }^{34}$ led to more systematic and detailed studies of haemodynamic function after acute myocardial infarction ${ }^{5}$ and the description of the syndrome of right ventricular infarction in 1974 by Cohn and his associates. ${ }^{6}$ But surprisingly little has been written about the practical details of the management of such patients and there are few published reports of such cases.

We describe 18 patients with severe circulatory collapse after acute myocardial infarction who were found on invasive monitoring to have a normal or low pulmonary artery wedge pressure. In particular we give details of the correction of hypoxia, plasma volume expansion, and use of inotropic agents.

Requests for reprints to Dr Denis Edwards, Intensive Care Unit, Withington Hospital, Nell Lane, Manchester M20 8LR.

Accepted for publication 17 February 1986

\section{Patients and methods}

We studied 18 patients managed on the intensive care unit or coronary care unit of Withington Hospital, Manchester (Table 1). In all of them shock had developed after acute myocardial infarction and they had a pulmonary artery wedge pressure of $\leqslant 14-18 \mathrm{~mm} \mathrm{Hg}$. Shock was defined as a systolic blood pressure of $\leqslant 80 \mathrm{~mm} \mathrm{Hg}$ associated with signs of hypoperfusion-that is disordered conscious level and oliguria of $\leqslant 20 \mathrm{ml}$ per hour. Cardiac output was estimated in seven patients and in these shock was further defined as a cardiac index of $\leqslant 1.81 / \mathrm{min} / \mathrm{m}^{2}$ in accordance with previous studies. ${ }^{5} 7$ A pulmonary artery wedge pressure of $14-18 \mathrm{~mm} \mathrm{Hg}$ was deemed to be the optimum level of preload for the left ventricle after acute myocardial infarction in terms of balancing cardiac output and tissue perfusion against the risk of cardiogenic pulmonary oedema. ${ }^{78}$ No patients had been on long term diuretic treatment before admission to hospital and only one had received a $\beta$ blocker.

MEASUREMENTS OF PULMONARY ARTERY

WEDGE PRESSURE

Mean pulmonary artery wedge pressure was mea- 
Table 1 Data on patients

\begin{tabular}{|c|c|c|c|c|c|c|c|}
\hline Case no & Age (yr) & Sex & $\begin{array}{l}\text { Heart rate } \\
\text { (beats/min) }\end{array}$ & Arrhythmias & $\begin{array}{l}R A P \\
(m m H g)\end{array}$ & $\begin{array}{l}P A W P \\
(m m H g)\end{array}$ & Outcome \\
\hline $\begin{array}{r}1 \\
2 \\
3 \\
4 \\
5 \\
6 \\
7 \\
8 \\
9 \\
10 \\
11 \\
12 \\
13 \\
14 \\
15 \\
16 \\
17 \\
18\end{array}$ & $\begin{array}{l}63 \\
64 \\
66 \\
70 \\
68 \\
64 \\
54 \\
57 \\
69 \\
51 \\
69 \\
53 \\
59 \\
53 \\
50 \\
62 \\
51 \\
53\end{array}$ & $\begin{array}{l}\mathbf{M} \\
\mathbf{M} \\
\mathbf{M} \\
\mathbf{F} \\
\mathbf{F} \\
\mathbf{M} \\
\mathbf{M} \\
\mathbf{M} \\
\mathbf{F} \\
\mathbf{F} \\
\mathbf{F} \\
\mathbf{F} \\
\mathbf{M} \\
\mathbf{M} \\
\mathbf{M} \\
\mathbf{M} \\
\mathbf{M} \\
\mathbf{F}\end{array}$ & $\begin{array}{r}100 \\
100 \\
150 \\
120 \\
100 \\
50 \\
100 \\
80 \\
40 \\
90 \\
50 \\
140 \\
70 \\
80 \\
110 \\
120 \\
115 \\
40\end{array}$ & $\begin{array}{l}\text { AF } \\
\text { VF } \\
\text { VF } \\
\text { AF } \\
\text { AF } \\
\text { AF, VF, CHB } \\
\text { VT } \\
\overline{C H B} \\
\overline{\text { AF }}, 2^{\circ} \mathrm{HB} \\
\overline{\mathrm{VF}} \\
\mathrm{VF} \\
\mathrm{VF} \\
\text { VF } \\
\mathrm{AF} \\
\mathrm{CHB}, \mathrm{VF}, \mathrm{AF}\end{array}$ & $\begin{array}{r}15 \\
12 \\
8 \\
17 \\
14 \\
17 \\
14 \\
14 \\
12 \\
9 \\
18 \\
16 \\
14 \\
15 \\
12 \\
14 \\
15 \\
15\end{array}$ & $\begin{array}{r}7 \\
4 \\
' 0 ' \\
15 \\
10 \\
6 \\
11 \\
14 \\
5 \\
5 \\
18 \\
16 \\
12 \\
10 \\
5 \\
' 0 ' \\
8 \\
6\end{array}$ & $\begin{array}{l}\text { S } \\
\text { D } \\
\text { D } \\
\text { S } \\
D \\
\text { S } \\
\text { S } \\
\text { D } \\
D \\
\text { S } \\
\text { S } \\
\text { S } \\
\text { S } \\
\text { S } \\
\text { S } \\
\text { S } \\
\text { S } \\
S\end{array}$ \\
\hline
\end{tabular}

AF, atrial fibrillation; VF, ventricular fibrillation; VT, ventricular tachycardia; CHB, complete heart block; $2^{\circ} \mathrm{HB}$, second degree heart block; RAP, right atrial pressure; PAWP, pulmonary artery wedge pressure; S, survived; D, died.

sured with reference to the phlebostatic axis (at the fourth intercostal space in the mid-axillary line) at end expiration (whether spontaneous or mechanical). The pulmonary artery catheters were supplied by Edwards Laboratories and were used with monitoring equipment supplied by Simonsen and Weel. Cardiac output was measured by a standard thermodilution technique with an Edwards Laboratories thermal dilution cardiac output computer (model 9520A).

\section{PATIENT MANAGEMENT}

When the pulmonary artery wedge pressure was $<14 \mathrm{~mm} \mathrm{Hg} 200 \mathrm{ml}$ of fluid was infused into a central venous catheter every 10 minutes. We adjusted plasma volume expansion according to clinical response and measurements of pulmonary artery wedge pressure (and cardiac output if available). Inotropic support was started if restoration of the pulmonary artery wedge pressure to $14-18 \mathrm{~mm} \mathrm{Hg}$ did not improve or reverse the signs of hypoperfusion. Dopamine was infused through a central venous catheter at an initial dose of $2 \mu \mathrm{g} / \mathrm{kg} / \mathrm{min}$; this was increased by $2 \mu \mathrm{g} / \mathrm{kg} / \mathrm{min}$ every $5 \mathrm{~min}$ depending on the response.
Wherever necessary, cardiac rate and rhythm were restored to normal before or after production of an optimum pulmonary artery wedge pressure depending on individual clinical circumstances. Blood gases were measured in samples taken from the brachial artery as soon as possible during resuscitation, and the patient's percentage inspired oxygen concentration was noted.

All patients had standard 12 lead electrocardiographs which were repeated serially wherever possible, and plasma creatine kinase was measured daily for three days.

\section{Results}

We noted right atrial pressure when the pulmonary artery catheter was inserted. In all patients this equalled or exceeded the pulmonary artery wedge pressure. The duration of hypotension before invasive monitoring was started varied from $30 \mathrm{~min}$ to $72 \mathrm{~h}$.

\section{ELECTROCARDIOGRAPHIC AND ENZYME}

CHANGES

Only patients with transmural infarction, as defined

Table 2 Arterial $\mathrm{PO}_{2}$ and percentage inspired oxygen in patients in cardiogenic shock

\begin{tabular}{|c|c|c|c|c|c|}
\hline Case no & $\% \mathrm{O}_{2}$ & $\mathrm{PO}_{2}(\mathrm{kPa})$ & Case no & $\% \mathrm{O}_{2}$ & $\mathrm{PO}_{2}(\mathrm{kPa})$ \\
\hline $\begin{array}{l}1 \\
2 \\
3 \\
4 \\
5 \\
6 \\
7 \\
8\end{array}$ & $\begin{array}{l}60 \\
60 \\
21 \\
60 \\
60 \\
60 \\
60 \\
50\end{array}$ & $\begin{array}{r}22.4 \\
8.3 \\
5.9 \\
19.2 \\
19.1 \\
5.7 \\
23.3 \\
7.1\end{array}$ & $\begin{array}{l}9 \\
12 \\
13 \\
15 \\
16 \\
17 \\
18\end{array}$ & $\begin{array}{l}40 \\
21 \\
60 \\
60 \\
60 \\
60 \\
21\end{array}$ & $\begin{array}{r}8.4 \\
7.2 \\
4.5 \\
7.3 \\
6.9 \\
11.9 \\
7.3\end{array}$ \\
\hline
\end{tabular}


Table 3 Pulmonary artery wedge pressure (PAWP) before resuscitation, volume of fluid required to produce an optimal $P A W P$, systolic blood pressure, and urine output in patients who responded to plasma volume expansion (group $A$ ) and those who required inotropic support (group B)

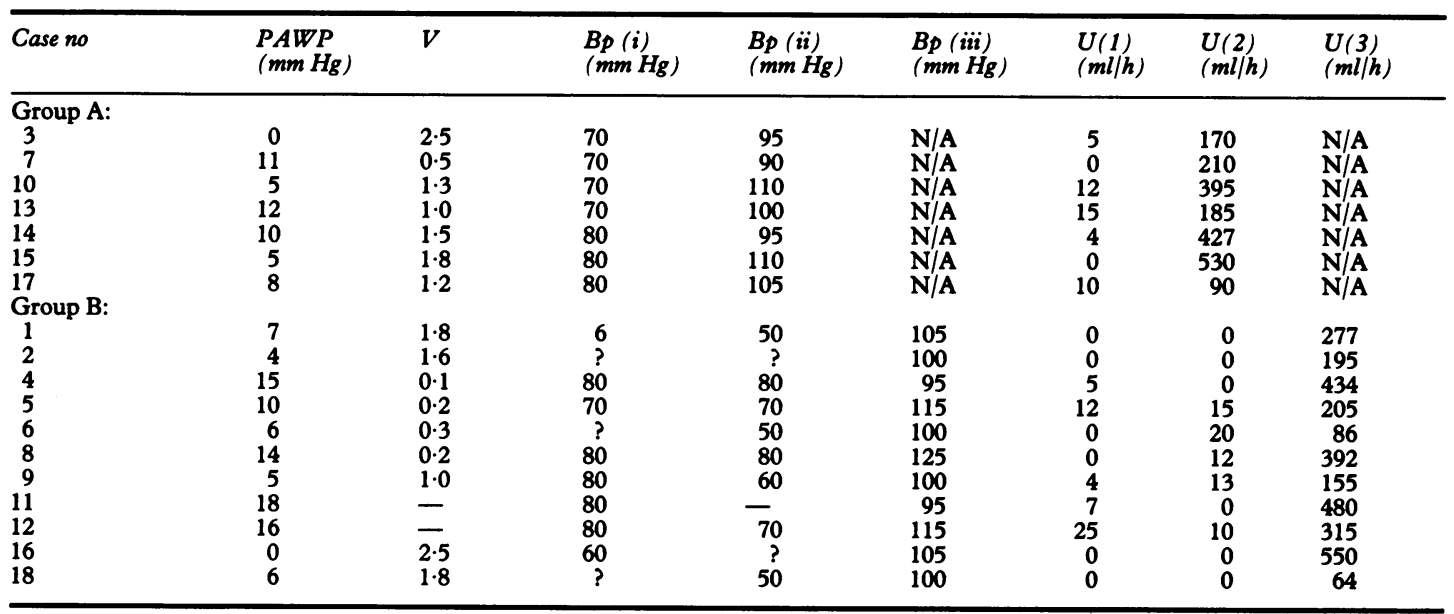

$\mathrm{V}$, volume of fluid in litres needed to produce an optimum pulmonary artery wedge pressure; Bp, systolic blood pressure (i) before resuscitation, (ii) after plasma volume expansion to an optimum pulmonary artery wedge pressure, and (iii) after dopamine. $U$, urine output (1) before plasma volume expansion, (2) after plasma volume expansion, and (3) after dopamine. ?, unrecordably low; N/A, not applicable.

by the appearance of abnormal $Q$ waves in the appropriate leads together with the classic progression of ST segment and T wave changes, were studied. Eleven patients had pure inferior wall changes (leads II, III, and aVF only), three had inferolateral changes (II, III, aVF, plus leads I and aVL or V5 and V6 or both) and four had anteroseptal changes (leads V1, V2, and V3). The maximum creatine kinase concentration in the first three days varied from $1200 \mathrm{iu} / 1$ to $3175 \mathrm{iu} / 1$ (normal range for our laboratory up to $400 \mathrm{iu} / \mathrm{l}$ ).

\section{HY POXIA}

Table 2 shows the values of arterial $\mathrm{PO}_{2}$. Ten patients had $\mathrm{PO}_{2}$ levels below normal $(11 \mathrm{kPa})$. The remaining eight patients were receiving approximately $60 \%$ oxygen and although they had $\mathrm{PO}_{2}$ values above $11 \mathrm{kPa}$ these were considerably lower than would be expected if pulmonary gas exchange were normal. ${ }^{9}$ They were thus potentially hypoxic and would certainly have been so had they been breathing room air. Three patients had inadequate alveolar ventilation as shown by the values of arterial $\mathrm{PCO}_{2}$ ranging from 6.5 to $13 \mathrm{kPa}$. None of these had a history of chronic disease and none had received opiates. In all patients $\mathrm{PO}_{2}$ and $\mathrm{PCO}_{2}$ values were normal after recovery. Six patients required endotracheal intubation and mechanical ventilation for periods ranging from $30 \mathrm{~min}$ to four days.

PLASMA VOLUME EXPANSION

In Table 3 the patients have been divided into two groups-that is those who responded to plasma volume expansion (group A) and those who did not and required inotropic support (group B). There were no significant differences in the mean values of pulmonary artery wedge pressure, systolic blood pressure, and urine output before resuscitation between the two groups and it was thus impossible to predict whether there would be a satisfactory response to plasma volume expansion alone. The volume required to produce an optimum pulmonary artery wedge pressure varied widely (Table 3 ). The amount was not related to the level of pulmonary artery wedge pressure or the severity of hypotension. The pronounced variation in the rate of rise of pulmonary artery wedge pressure in response to fluid challenge made continuous bedside monitoring mandatory in all patients. This variation can further be demonstrated by considering in more detail the responses of two patients with similar levels of pulmonary artery wedge pressure (Figure). Three of the five patients who died developed circulatory collapse immediately after receiving intravenous frusemide.

Plasma volume expansion reversed the signs of hypoperfusion in seven patients. Eleven patients needed additional inotropic support. The dose of dopamine varied from 2 to $18 \mu \mathrm{g} / \mathrm{kg} / \mathrm{min}$. In only one patient was the use of dopamine associated with a critical rise in pulmonary artery wedge pressure. Because of the well recognised lag between an improvement in cardiac output and detectable changes in blood pressure the dose of dopamine was 


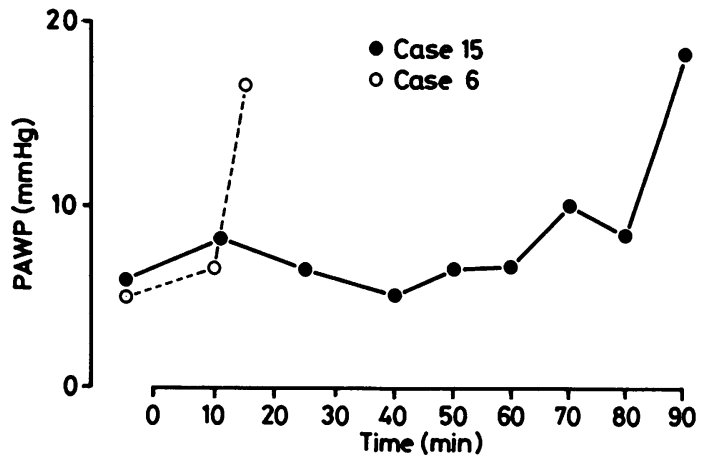

Figure Response of pulmonary artery wedge pressure $(P A W P)$ to plasma volume expansion in cases 15 and 6.

increased only until the cardiac index was greater than $2.21 / \mathrm{min} / \mathrm{m}^{2}$ or there had been an improvement in the patient's conscious level. Urine output started to improve $30-75$ minutes after this point. Dopamine was needed for $72-120$ hours in those patients who survived.

\section{Discussion}

In a classic study Forrester divided patients with acute myocardial infarction into four haemodynamic subsets based on measurements of cardiac index (CI) in $1 / \mathrm{min} / \mathrm{m}^{2}$ and pulmonary artery wedge pressure (PAWP) in $\mathrm{mm} \mathrm{Hg}{ }^{5}$ The patients were classified thus-group I, CI $>2.2$ and PAWP $<18$, group II, CI $>2 \cdot 2$ and PAWP $>18$, group III, CI $<2.2$ and PAWP $<18$, group IV, CI $<2.2$ and PAWP $>18$. Our patients fall into group III of this classification. They also fulfil the criteria of the definition of the syndrome of right ventricular infarction as laid down by Cohn et al. ${ }^{6}$ This is suspected clinically when there is hypotension, hypoperfusion, and high jugular venous pressure, and lack of clinical or radiological features of left ventricular failure usually after inferior wall infarction and has been described as "....a right atrial pressure as high or higher than simultaneously measured pulmonary artery wedge pressure...". ${ }^{10}$ In view of the large number of patients in this series as compared with others we feel able to comment on management in some detail.

The first step is to correct hypoxia which is very common and often severe. In shock associated with right ventricular infarction hypoxia this is of fundamental importance for two reasons. Firstly alveolar hypoxia increases pulmonary vascular resistance and hence the afterload of the right ventricle. Secondly in order to improve venous return and to facilitate insertion of pulmonary artery catheters or pacing electrodes all patients must be placed in the head down position. In the age groups affected this will reduce pulmonary functional residual capacity and cause or exacerbate hypoxia. ${ }^{11}$ Six patients could not tolerate the horizontal position and they had to be intubated and mechanically ventilated before the insertion of intravascular catheters. Other causes of the hypoxia that is seen so frequently must remain speculative, but a possible mechanism is a reduction in mixed venous $\mathrm{PO}_{2}$ as a result of a low cardiac output. Pre-existing left ventricular failure was thought to be the explanation in only one patient. Thus we recommend that wherever it is feasible arterial blood gases should be measured in such patients before the insertion of pulmonary artery catheters or pacing electrodes. If hypoxia is severe then the equipment, drugs, and personnel necessary for emergency endotracheal intubation should be available. We have been unable to find any other systematic study of the incidence or severity of hypoxia in patients with shock due to right ventricular infarction.

After correction of hypoxia the next step is to measure pulmonary artery wedge pressure and if it is low to raise it to an optimum level with controlled volume expansion. Opinions differ on the safety and effectiveness of colloid of crystalloid fluids. We used Hartmann's solution and a gelatin derivative in equal volumes believing that it is not the type of fluid but the precise volume as determined by measurement of pulmonary artery wedge pressure that is important. The central venous pressure is not a reliable guide for fluid therapy after acute myocardial infarction. ${ }^{12}$ Right ventricular infarction rarely occurs in isolation, left ventricular involvement being common and often severe. ${ }^{13}$ Because of the slopes of the left ventricular function and pressure/volume curves and the reduction in left ventricular compliance a low pulmonary artery wedge pressure has a pronounced effect on stroke volume. The optimum pulmonary artery wedge pressure tends to be higher than normal, falling just short of those levels which would give rise to cardiogenic oedema. As a result of this "brittle" response to volume expansion the risk of over transfusion is high during unmonitored treatment.

If the left ventricular preload is low and reduced further then catastrophic falls in stroke volume and cardiac output can occur. This explains the disastrous effects of intravenous frusemide seen in five patients. Collapse occurred within minutes, without a diuresis and was presumably related to the peripheral haemodynamic effects of frusemide. ${ }^{14}$ None of these five patients had clinical or radiological evidence of left ventricular failure, and frusemide had been given because of raised jugular venous pressure. In retrospect the clinicians involved agreed 
that the diuretic was inappropriate.

If an optimal pulmonary artery wedge pressure does not bring about a rise in cardiac output or reversal of hypoperfusion then inotropic support is needed. We used dopamine as described above and found that it rarely caused a critical rise in pulmonary artery wedge pressure as it does in other forms of cardiogenic shock. ${ }^{15}$

After restoration of renal perfusion all surviving patients had a diuretic phase. Monitoring of pulmonary artery wedge pressure was continued throughout this phase, which lasted from 12 to $72 \mathrm{~h}$, in order to maintain a safe left ventricular preload.

Arrhythmias were common and often life threatening. The stage at which the arrhythmias were treated depended on individual circumstances, with for instance ventricular fibrillation dictating its own treatment priority. Previous studies have contained a very high proportion of patients with complete heart block. The relatively high incidence of ventricular fibrillation in this series is therefore a new finding. Two patients (cases 15 and 18) developed recurrent ventricular fibrillation despite large doses of lignocaine, and stable sinus rhythm was restored only after hypoxia and shock had been reversed by mechanical ventilation and dopamine. Both these patients survived. Four patients required temporary transvenous pacing electrodes and these were inserted immediately before the pulmonary artery catheters. As in previous studies ${ }^{16}$ the response to pacing alone was disappointing; perfusion improved only after correction of haemodynamic function with fluid and dopamine.

Cases of cardiogenic shock in which left ventricular end diastolic pressure is not critically raised therefore require aggressive management and the facilities of a modern coronary care unit or intensive care unit. All the patients who survived are alive and well and only one requires medication for heart failure. We feel that the more favourable prognosis in this form of cardiogenic shock, compared with other forms, justifies such an approach.

\section{References}

1 Allen NH, Danzig R, Swan HJC. Incidence and significance of relative hypovolaemia as a cause of shock associated with acute myocardial infarction. Circulation 1967; 40 (suppl 2): 50.

2 Nixon PGF, Ikram H, Norton S. Cardiogenic shock treated with infusion of dextrose solution. Am Heart $\mathcal{f}$ 1967; 73: 843-5.

3 Swan HJC, Ganz W, Forrester J, Marcus H, Diamond $G$, Chonette D. Catherization of the heart in man with use of a flow-directed balloon tipped catheter. $N$ Engl $\mathcal{F}$ Med 1970; 283: 447-51.

4 Forrester JS, Ganz W, Diamond G, McHugh T, Chonette D, Swan HJC. Thermodilution cardiac output determination with a single flow-directed catheter. Am Heart f 1972; 83: 306-11.

5 Forrester JS, Diamond GS, Swan HJC. Correlative classification of clinical and haemodynamic function after acute myocardial infarction. Am $₹$ Cardiol 1977; 39: 137-45.

6 Cohn JN, Guiha NH, Broder MI, Limas CJ. Right ventricular infarction. Clinical and haemodynamic features. Am f Cardiol 1974; 33: 209-14.

7 Forrester JS, Diamond G, Chatterjee K, Swan HJC. Medical therapy of acute myocardial infarction by application of haemodynamic subsets. $N$ Engl $\mathcal{F}$ Med 1976; 295: 1356-62.

8 Crexells C, Chatterjee K, Forrester JS, Dikshit K, Swan HJC. Optimal level of filling pressure in the left side of the heart in acute myocardial infarction. $N$ Engl f Med 1973; 24: 1263-6.

9 Nunn JF. Oxygen in applied respiratory physiology. 2nd ed. London: Butterworth, 1977.

10 Cohn JN. Right ventricular infarction revisited. $A m \mathcal{F}$ Cardiol 1979; 43: 666-8.

11 Nunn JF. Elastic resistance to ventilation in applied respiratory physiology. 2nd ed. London: Butterworth, 1977.

12 Forrester JS, Diamond G, McHugh T, Swan HJC. Filling pressures in the right and left sides of the heart in acute myocardial infarction-a reappraisal of central venous pressure monitoring. $N$ Engl f Med 1981; 28: 190-3.

13 Wartmann WB, Hellerstein HK. The incidence of heart disease in 2,000 consecutive autopsies. Ann Intern Med 1948; 28: 41-65.

14 Dikshit K, Vyden JK, Forrester JS, Chatterjee K, Prakash R, Swan HJC. Renal and extrarenal haemodynamic effects of frusemide in congestive cardiac failure after acute myocardial infarction. $N$ Engl $\mathcal{F}$ Med 1973; 288: 1087-90.

15 Timmis AD, Fowler MB, Chamberlain DA. Comparison of haemodynamic responses to dopamine and salbutamol in severe cardiogenic shock complicating acute myocardial infarction. Br Med f 1981; 282: 7-9.

16 Nixon $P$, Ikram $H$, Morton S. Infusion of dextrose solution in cardiogenic shock. Lancet 1966; 1: 1077-9. 